\title{
INVESTIGATION OF THE USE OF LEAN CONSTRUCTION PRACTICES IN TRANSPORTATION CONSTRUCTION PROJECTS
}

\author{
Mohammad R.A.H. Al Heet ${ }^{1}$, Thais da C. L. Alves ${ }^{2}$, and Nensi Lakrori ${ }^{3}$
}

\begin{abstract}
The use of Lean Construction (LC) concepts and tools has advanced in different sectors in the United States, including but not limited to, delivery of commercial, educational, and hospital buildings. Many contractors working on these sectors appear to use more collaborative forms of contracts and have been more willing to experimenting with LC. However, in the transportation sector Lean Construction appears to be in its early phases of adoption. This sector has used tools aiming at fostering collaboration which are developed based on recommendations from departments of transportation in different states. Yet, the sector has not embraced Lean practices that could support the design, planning, and construction of these projects. This study aimed at identifying management practices used by organizations building or managing the construction of transportation projects in Southern California and identifying opportunities to use Lean practices to deliver these projects. Interviews were carried out with contractors, owners, and consultants and later categorized to identify the practices used, gaps where LC practices could be implemented, and the level of maturity of the organizations investigated regarding the use of Lean Construction practices. Findings revealed that organizations use collaborative practices, visual management tools, $5 \mathrm{~S}$, and root cause analysis to investigate problems.
\end{abstract}

\section{KEYWORDS}

Continuous Improvement, Collaboration, Lean Construction, Transportation

\section{INTRODUCTION}

Transportation projects are essential to the development and growth of cities as they connect and create access to communities. Despite their importance, these projects are usually lengthy, geographically larger, with projects often spanning across several miles, costly, and disruptive to the surrounding communities. Transportation projects are notoriously known for cost and schedule overruns, and their vast impact on the economy and the creation of transportation active zones. Yet these projects are necessary to

1 Former graduate student, MS, Dept. of Civil, Construction, and Environmental Engineering, San Diego State University, mohammadheet@hotmail.com, orcid.org/0000-0002-5314-8338

2 Associate Prof., Ph.D., AGC-Paul S. Roel Chair in Const. Eng. and Mgmt., Dept. of Civil, Const., and Env. Eng., San Diego State University, talves@sdsu.edu , orcid.org/0000-0001-7928-9190

3 Full-time Lecturer, PE, MS, LEED BD+C, Dept. of Civil, Construction, and Environmental Engineering, San Diego State University, nlakrori@sdsu.edu, orcid.org/0000-0002-7168-0280 
improve connectivity between communities and promote a healthy flow of goods and passengers to support the economy. Considering these issues, the Senate Bill 1 (SB1) Road Repair and Accountability Act was signed into law in 2017 in the State of California. SB1 supports projects related to road rehabilitation, congestion relief, trade corridor improvements, and improved transit and rail travel to address one of California's most pressing issues: its transportation system (Rebuilding California 2020). Given the magnitude of this program, with billions of dollars allocated to the improvement of transportation systems in California, the authors discuss the results of a study to investigate the use of Lean practices in transportation projects in Southern California, and to identify opportunities to improve these projects with the use of Lean Construction tools and processes. The public sector and private contractors are often blamed for the overruns experienced in these types of projects, but little is done to alleviate the causes of these problems.

This paper presents studies documented in the literature that have identified common problems in transportation projects, followed by the description of the method used to conduct the study, and finally the description of important points captured from interviews, especially focusing on how the projects are scheduled, and how plans are developed and shared with its stakeholders. The goals of this study were two-fold: 1 . investigate management practices currently used to deliver transportation projects in California; 2. identify opportunities where Lean Construction practices can be applied to streamline the delivery of these projects.

\section{TRANSPORTATION PROJECTS, CHALLENGES AND EFFORTS TO IMPLEMENT LEAN}

Transportation projects can be categorized into a few major areas, including the ones considered in this study: highway construction, bridges, and transit. According to the FHWA (2017), there are three types of roadway construction: new construction, reconstruction, and Resurfacing, Restoration and Relabiliation (3R). New Construction encompasses roadways that are built on new alignment, whereas reconstruction involves roadways that are reconstructed along existing alignment, involving full-depth pavement replacement, adding lanes adjacent to an existing lane, changing the character of a roadway (e.g., converting a two-lane highway to a multi-lane highway), and/or reorganizing interchanges and intersections. 3R or resurfacing, restoration, and rehabilitation projects often include pavement improvement work and safety improvements, while maintaining the existing alignment. Bridges are another type of transportation project with the aim to connecting new or existing roads. Finally, transit systems are designed and built to transport people and/or goods and comprise of rapid transit, commuter rail, metro, subway, light rail, heavy rail, trams, tube, suspension railways or underground rail.

\section{Common Challenges in Transportation Projects}

The study of challenges encountered in transportation projects is documented in the literature. It is worth noting that not all challenges discussed herein affect all infrastructure and transportation projects, and some of these projects might have seemless project deliveries; however, this section focuses on common challenges identified in the literature and later observed in the projects discussed. Hasan et al. (2014) found that delays in infrastructure projects can be caused by any or all of the different stakeholders involved in these projects, i.e., owners, contractors, utility companies, and governmental 
agencies to name a few. The problems include improper planning and scheduling, poor communication and site management, and poorly defined scopes, which result in major changes and untimely decision-making. Additionally, Hasan et al. (2014) also point out issues related to utilities and long lead times to address information requests regarding the positioning of existing and planned/designed utilities, and delays related to permits and land acquisition. These issues are also closely related to constructability matters, which were identified by Goodrum et al. (2003) who also added traffic control, right-ofway commitments, and geotechnical issues to the long list of challenges facing these types of projects. In fact, 19 state transportation agencies, which participated in a survey developed by Goodrum et al. (2003), indicated that utilities are considered the most common constructability issue in their projects. Problems with utilities include difficulty finding the existing utilities prior to construction; construction delays due to relocations; unforeseen existing utilities that obstruct the construction; wrong utilities relocation; and plans not matching actual utility locations and subsurface depth.

According to another study carried out by Park and Papadopoulou (2012), the most significant and common cause of cost overruns in transportation infrastructure projects is "awarding contracts to the lowest bidder". By leveling the playing field using the lowest cost as the deciding factor to award a contract, owners end up paying more and not attaining the most qualified team to build the projects. This practice directly affects the quality of life, safety and health of citizens in surrounding communities, which bear the indirect costs of mismanaged transportation projects. In addition to the causes elicited by Hasan et al. (2014), presented above, other causes can be attributed to cost overruns in transportation projects including, but not limited to, unforeseen site conditions, inadequate pre-construction studies, inappropriate construction methods, subcontractors and related procurement contracts, schedule acceleration required by client, labor shortages, delayed or slow inspection of work, and shortages of materials (Park and Papadopoulou 2012).

\section{Potential Solutions}

The authors used Lean Construction (LC) as a theoretical framework while searching for potential solutions to address the problems identified in the literature reviewed. LC can be broadly defined as a new production philosophy originated in the manufacturing industry and translated to the construction industry focusing on generating value, eliminating waste, and promoting flow in construction-related systems. Common practices associated with LC include, but are not limited to: Plan-Do-Check-Act (PDCA) cycles or similar tools to promote continuous improvement; the Last Planner ${ }^{\circledR}$ System (LPS); visual management practices to increase transparency; just-in-time delivery (JIT); value stream mapping (VSM); and use of 5 whys among others (Koskela 1992).

The literature reviewed points to more holistic and collaborative approaches to be used in transportation projects (e.g., Hasan et al. 2014 and Love et al. 2015), however, few actually indicate LC practices to support better project delivery. Hanna et al. (2010) specified that state highway agencies were not using Lean practices, e.g., JIT, LPS, VSM, and pointed out tools that could improve the delivery of these projects. Tezel et al. (2016) described the benefits of using visual management practices and tools, e.g., 5S, performance boards to keep track of metrics and manage traffic, in the transportation sector and their results including increased coordination, self-management, and, improved site conditions to name a few. 
Some of these Lean tools and techniques are currently being used by Highways England (HE), which is a government owned organization in the United Kingdom (UK) in charge of modernizing, maintaining and operating the highways in the UK (Highways England 2016). HE is utilizing Lean tools and techniques to design and improve their processes across the transportation industry including collaborative planning; visual management; problem solving; benefits realization; and transparency (Highways England 2016). By using Lean to improve internal processes and efficiency of road construction projects, HE managed to achieve benefits for a return on investment (ROI) greater than 20:1 and over eighty-million-pound sterling in efficiency savings (Fullalove 2013). Another notable example is the Transportation Lean Forum (TLF), part of the Colorado Department of Transportation in the United States. The TLF is a collaborative which supports continuous improvement based on Lean practices and provides specific examples applied to the sector via idea cards shared by contributors (TLF 2020).

\section{RESEARCH METHOD}

The research method comprised a review of the literature on challenges facing transportation projects and the potential implementation of solutions grounded on LC, followed by the development of a research protocol including the interviews and site visits. Finally, data analysis to code answers into major categories and mapping them to LC practices as potential solutions is also presented in this paper.

Initially, a literature review on the topics of Lean Construction and its application to transportation projects and the development of a research protocol were submitted for review and approval by the Institutional Review Board (IRB) at San Diego State University. The protocol (HS-2017-0178) was reviewed and considered exempt. After this initial phase, the first author conducted interviews and site visits, whenever possible, and discussed the progress with the second author (MS thesis advisor), who also participated in a few interviews. An informed consent document was shared with the interviewees aiming at informing them about the research goals, associated risks, and the handling of the data collected. An interview guide shown in the Appendix used a semistructured interview approach in which the researcher had a set of pre-defined questions that would allow the investigation of additional relevant details shared by the interviewee (Fellows and Liu 2008). Interviewees were initially contacted from a list of personal contacts of the authors, and after the initial interviews the authors used a snowball approach relying on referrals from interviewees to reach out to new contacts. The subjects interviewed included managers, project executives, consultants, and designers from owner organizations and contractors/subcontractors of the projects investigated. The 11 listed interviews lasted mostly between $75-165$ mins, with one of them lasting 25 minutes as it was related to clarifications asked from an additional interviewee about one of the projects visited. Interviews were carried out over the phone or at construction project site offices, and the first author would take notes during the interviews. Eventually, the first author would take pictures of site artifacts related to the management of the projects, when allowed by the interviewees (and outlined in the informed consent). The interviews focused on challenges faced by and practices implemented on the projects interviewees were talking about, or had experience with, and their use in transportation projects. The goal was not to capture the participants perceptions of these practices, but rather to identify what, when, where, why, and how these practices were being used.

Finally, the data was analyzed and discussed in detail in the first author's master's thesis (Al Heet 2018) and revised with comments and support provided by the thesis 
advisor and members of the MS thesis committee, which included the third author. Responses provided by each interviewee to each question of the interview guide were organized in short case descriptions including: the demographics of the project; main challenges associated with the project, as reported by the interviewee, and how they are being addressed; and details about the management of design and construction of the project (e.g., scheduling, planning, collaboration initiatives, safety, procurement of materials, use of visual management artifacts). Once the responses were organized in these short case descriptions, a summary of the responses was compiled in a tabular format to allow for comparisons.

This exploratory study used different approaches to address validity concerns adapted from Yin's (2009) recommendations for case study research. Construct validity was addressed by selecting interviewees from three different types of transportation projects (i.e., highway, bridge, and transit) with different professional attributions (e.g., engineers, consultants, project managers, operation managers, owners). Internal validity was addressed by finding recurring topics in the discussion and matching the patterns identified within the interviewees' responses and the literature. External validity was addressed by using the same interview questions and research protocol throughout the process, similarly that helped with concerns related to reliability.

\section{ANALYSIS OF INTERVIEWS}

Initially, answers to the ten interviews with seven organizations were analyzed individually to characterize each project and their peculiarities. Later, the information provided by interviewees in each interview was cross analyzed in search for trends and common issues faced by these projects. The main bins used to categorize the information were related to the questions asked during the interview (see Appendix - Interview Protocol), namely: project description challenges facing the project and how they were addressed; management of design and construction; approach to the project planning and scheduling, including the management of materials. A summary with the demographics of the reference projects described by the interviewees is shown in Table 1.

Interview I addressed a road project with an estimated duration of 26 months, which ended up taking 30 months to completion. Safety improvements to this road were critical as fatal accidents had claimed lives around the time the project was being planned. This project included the addition of pedestrian/equestrian trails, improvement of storm drains, upgrade of utilities, and environmentally related tasks (e.g., monitoring the habitat, and off-site mitigation). Among the challenges encountered were construction staging while the road in full operation; coordination with multiple stakeholders (e.g., utilities, permitting, third party providers, CalFire, California Highway Patrol, local homeowners association to name a few); night time work. A critical path method (CPM) schedule was used as well as a 3-week lookahead plan, which was linked to the master schedule. Subcontractors did not participate in the development of the master schedule. The standard procedures used by Company A in this project were related to reporting (e.g., cost estimates, document management, reports). Some boards displayed basic information in the office (e.g., rebar placement, crane limits).

Interview II covered a bridge replacement project, planned to happen in two phases to allow for construction of part of the new bridge, while keeping an existing one operational, followed by the construction of the rest of the new bridge and demolition of the old one. Some of the challenges in this project included: delays in the work performed by a cable company involving the relocation of cables; design flaws, which did not match the 
existing groundwater level sitting three feet below grade. The master schedule was developed between the project manager (PM) and discussed with the superintendent, who would identify any necessary revisions; a 3-week lookahead schedule was also used during weekly meetings. Similarly to what was reported in Interview I, standards were also related to reporting.

Table 1: Project Characteristics

\begin{tabular}{|c|c|c|c|c|c|}
\hline Interview & Company & Project Type* & $\begin{array}{l}\text { Total Project } \\
\text { Cost in } \\
\text { Million US\$ }\end{array}$ & $\begin{array}{l}\text { Duration } \\
\text { (Months) }\end{array}$ & $\begin{array}{l}\text { Delivery } \\
\text { Method }\end{array}$ \\
\hline I & A & Highway & 26.50 & 30 & DBB \\
\hline II & A & Bridge, Highway & 16 & 23 & DBB \\
\hline III & A & $\begin{array}{c}\text { Bridge, Highway, and } \\
\text { Transit }\end{array}$ & 700 & 48 & $\mathrm{CM} / \mathrm{GC}$ \\
\hline IV & B & Highway & 9 & 28 & DBB \\
\hline V & B & $\begin{array}{c}\text { (Continuous improvement } \\
\text { program) }\end{array}$ & & & \\
\hline VI & C & $\begin{array}{c}\text { Bridge, Highway, and } \\
\text { Transit }\end{array}$ & 1,200 & 56 & $\mathrm{CM} / \mathrm{GC}$ \\
\hline VII & D & Highway & 22 & 24 & DBB \\
\hline VIII & $E$ & Transit & 237 & 35 & $\mathrm{CM} / \mathrm{GC}$ \\
\hline IX & $\mathrm{F}$ & $\begin{array}{l}\text { Bridge, Road } \\
\text { Improvement }\end{array}$ & 43.5 & 31 & DBB \\
\hline$x$ & Dot & $\begin{array}{l}\text { (Multiple projects - } \\
\text { Institutional view) }\end{array}$ & & & \\
\hline
\end{tabular}

*Most projects are located in Southern California, except for Interview VII located in the Northeastern States. DoT=Department of Transportationl DBB=Design-Bid-Build; DB=Design-Build; $\mathrm{CM} / \mathrm{GC}=$ Construction Management at Risk.

Interview III referred to a road and transit improvement project, considering transportation, environmental and coastal access projects. This project included, but was not limited to, 27 miles of express lanes, 30 overpasses, bridge replacements, and enhancements to the local rail system. This project was being built by a joint venture (JV) bringing together three large general contractors under the Construction Manager/General Contractor $(\mathrm{CM} / \mathrm{GC})$ delivery method. Due to the JV nature of the project, unifying the culture of the three firms was a challenge, as was keeping preconstruction decisions and expectations in line with the interests of companies, organizations, and individuals who joined the project later. The JV participants worked to select the most appropriate practices for this project and trained their personnel on the selected practices. Preconstruction meetings started two months after the project was awarded and continued for two years before construction started. The schedule was developed by the JV and negotiated with the owner, and it identified points where the schedule could be accelerated. A CPM schedule was developed to keep track of the project, and a 6-week lookahead schedule used to show more detailed activities. Engineers, superintendents and foremen discussed the execution details of the schedule. The project used white boards to communicate information to its participants. 
Interview $I V$ considered a project involving a rural freeway widening and a new traffic signal. This project was financed, designed, and managed by a developer and, after completion, handed to the local Department of Transportation (DoT) for operation. This project faced the lack of finalized plans and design issues related to the multiple stakeholders involved (e.g., five different utility companies, privately owned land). The definition of execution batches caused differences in the finished product, and the lack of continuity between the work being developed (e.g., one month of underground work followed by two months of roadwork) caused waiting periods for different trades. The master schedule showed large segments of work (e.g., drainage) whereas detailed schedules showed more comprehensive activities (e.g., 50 operations to be developed within the next three weeks). The project schedule development involved the project manager, the region superintendent and project superintendent, and the construction manager.

Interview $V$ focused on the continuous improvement (CI) program implemented by Company B. Company B involved the owner in early schedule decisions but did not use the LPS in planning activities. Project facilitators used the define, measure, analyze, improve, and control (DMAIC) technique to look for opportunities to reduce waste, inefficiencies and defects. The company conducted root cause analysis of problems using fish bone diagrams, brainstorming meetings to gather ideas to improve processes, Pareto charts to categorize data, benefits matrix (value vs. effort to implement a solution), $5 \mathrm{~S}$, and key performance indicators (KPIs) to track the CI program, e.g., percent plan complete (PPC), gross margin forecasted vs. revenue, OSHA recordable incident rate, and quality metrics.

Interview VI was related to a light rail project, spanning 56 months and costing over US $\$ 1.2$ billion. The project included light rail, aerial viaducts, stations, bridges, a tunnel, conversion of heavy rail from one to two tracks, new double tracks, and crossings of an interstate freeway. The project was led by a JV using the $\mathrm{CM} / \mathrm{GC}$ delivery method, with the JV (Company C) self-performing 60\% of the work. Challenges in this project included communication among the numerous stakeholders involved, keeping public and private stakeholders satisfied and informed, and schedule risks regarding the acquisition of right of way, utilities, permits, inter-agency agreements, and addressing design delays (RUPID, which was a term coined by one of the project team members). The JV evaluated the design/pricing decisions, schedule, and constructability issues during the preconstruction phases. The JV also co-located with the main subcontractors to help the teams stay involved with and kept abreast of decisions made regarding the project. The 6,000activity master schedule was collaboratively developed in a small working group with an expert in using Primavera, carefully capturing the input of the group to generate the project schedule. The team also used a milestone matrix (in MS Excel) to keep track of major milestones, without having to deal with the large master schedule. Moreover, the project was broken down into geographical reaches, which were large chunks of work acting like subprojects that could be completed independently. For instance, the authority that managed the railroad, which was part of this project, issued absolute work windows (AWWs) consisting of 56-hour periods when the tracks were closed for operation of trains allowing work to be scheduled on or close to the tracks during that time. Any work related to the tracks had to happen during AWWs and they were not issued during certain times of the year. Additionally, the RUPID constraints were discussed on a regular basis, and field engineers developed 6-week lookahead schedules, used to track progress against milestones, whereas project engineers developed 90-120 lookahead schedules. Project 
engineers had weekly meetings to address tasks for the coming week, and 30-minunte daily meetings with field engineers, superintendents, and foremen. The team used white boards on site to keep track of and distribute information about the schedule, weekly work plans, inspections, and deliveries, among others.

Interview VII was carried out with a GC (Company D) working on maintenance projects, rehabilitation of freeways and infrastructure projects, on the Northeast of United States. Challenges faced by this GC were related to manpower shortage, delays on deliveries and permits, and violation of safety rules incurring in additional project delays. The GC's project manager, chief operating office, and executive project manager developed the schedule, and did not involve subcontractors, project engineers or superintendents in this task. The superintendent developed daily "game plans" tracked daily alongside the use of materials, crews on site, use of equipment, and safety indicators. Company D used standard procedures that are common practices in the industry, e.g., safety orientations, training workshops for its employees.

Interview VIII was developed considering the work of a JV, which included Company $\mathrm{E}$ (subcontractor), using the $\mathrm{CM} / \mathrm{GC}$ delivery method. The work involved the construction of a new 4-track interlocking, modification of overhead catenary, installation of new drainage, switches, and crossover tracks. This company faced challenges related to coordinating the work of a third-party contractor and also design specifications regarding the material to be used. The JV in this case had the schedule developed by a consulting contractor, who asked for input from the owner, the JV, and subcontractors. Additionally, Company E developed 3-week lookahead schedules, and their superintendent and field engineer prepared weekly "game plans" to drive work. Visual management was not observed in this case.

Interview $I X$ involved a consultant who was part of a bridge and road improvement DBB construction project. The challenges in this project, as identified by the consultant, involved: weather conditions (e.g., no concrete placement when it was too windy or too hot); highway closures; event traffic caused by major events hosted around the project; change orders related to traffic handling plans, differing site conditions, electrical work, and signage, among others. As the construction manager of the project, the consultant developed their own master schedule and used it to keep the GC accountable.

Interview $X$ covered practices used by the state DoT, as discussed with one of its employees, and does not refer to any specific project. Regarding the scheduling of the project, DoT personnel meet with contractors to discuss staging of the work and alternative ways to perform tasks. The DoT personnel was also involved in constructability reviews which also impacted project schedules and plans. With regards to process improvement, the DoT had a Lean Six Sigma (LSS) team at its headquarters, and this team investigated problems that were brought to them and defined solutions to resolve the issues.

Once the interviews were concluded and analyzed, the results were organized in Table 2. These results outlined challenges indicated by different interviewees, where they were reported, and which tools and techniques from the Lean Construction literature could be used to alleviate or eliminate problems resulting from the challenges identified. The solutions to the challenges identified were obtained from the literature review, from the interviewees, and/or from the authors discussions of these problems. It is worth noting that the problems reported by the interviewees were similar in nature to those identified in the literature. Moreover, very few companies use LC practices across their projects or use LC tools in an isolated fashion. 


\section{MAin Findings AND Discussion OF USE OF LeAn In TRANSPORTATION PROJECTS}

The findings indicate some similarities between the LC practices reported in the literature and management practices reportedly used by the construction companies related to this study.

Table 2: Challenges and opportunities to implement Lean in the delivery of transportation projects

\begin{tabular}{|c|c|c|}
\hline Challenge & $\begin{array}{l}\text { Reported } \\
\text { on } \\
\text { Interview }\end{array}$ & Lean-inspired tools and techniques \\
\hline $\begin{array}{c}\text { Relocation and } \\
\text { positioning of utilities }\end{array}$ & $\begin{array}{l}\text { I, II, and } \\
\text { IV }\end{array}$ & $\begin{array}{c}\text { Use of tools to improve transparency including BIM, and } \\
\text { visual management techniques (e.g., boards) to report } \\
\text { issues and disseminate information }\end{array}$ \\
\hline $\begin{array}{l}\text { Communication with } \\
\text { and handling } \\
\text { needs/expectations of } \\
\text { multiple stakeholders } \\
\text { related to land use and } \\
\text { involved communities }\end{array}$ & $\begin{array}{l}\text { I, III, IV, } \\
\text { and VI }\end{array}$ & $\begin{array}{c}\text { Supporting collaborative relationships among stakeholders } \\
\text { through more collaborative delivery methods; use of } \\
\text { Choosing by Advantages and Benefit Realization } \\
\text { processes to capture needs, assess them and make } \\
\text { informed decisions. }\end{array}$ \\
\hline $\begin{array}{l}\text { Scheduling of crews } \\
\text { with interrelated work, } \\
\text { stop and go problems, } \\
\text { no continuous flow, } \\
\text { segmentation }\end{array}$ & I and IV & $\begin{array}{l}\text { Use of LPS-related concepts and tools to promote reliable } \\
\text { and continuous flows of work. Use of line of balance } \\
\text { schedules to promote flow and visualization of work. }\end{array}$ \\
\hline Shortage of manpower & VII & $\begin{array}{c}\text { Develop people through partnerships with local entities to } \\
\text { educate construction workers. Support organizations such } \\
\text { as The Beavers who promote goodwill, friendliness and } \\
\text { consideration within the heavy engineering construction } \\
\text { industry. }\end{array}$ \\
\hline $\begin{array}{l}\text { Design-related issues, } \\
\text { incomplete plans } \\
\text { and/or differing site } \\
\text { conditions, errors in } \\
\text { specifications }\end{array}$ & $\begin{array}{l}\mathrm{II}, \mathrm{IV} \text {, and } \\
\mathrm{VI}\end{array}$ & $\begin{array}{l}\text { Pilot/use more collaborative delivery methods to foster } \\
\text { early collaboration during the design stage. Use tools and } \\
\text { processes to improve communication and transparency } \\
\text { such as: BIM, co-locate design teams, use the 'big room' } \\
\text { format for design meetings. }\end{array}$ \\
\hline Risk Management & VI & $\begin{array}{l}\text { Document the items identified during RUPID- related } \\
\text { discussions and share visual information with project } \\
\text { stakeholders through boards, models, and animations. }\end{array}$ \\
\hline $\begin{array}{l}\text { Delays in deliveries } \\
\text { and permits }\end{array}$ & $\begin{array}{l}\mathrm{I}, \mathrm{IV} \text {, and } \\
\text { VII }\end{array}$ & $\begin{array}{l}\text { Promote early collaboration among team members and the } \\
\text { permitting agencies to identify critical needs regarding } \\
\text { permits. Share information about permit requirements. }\end{array}$ \\
\hline $\begin{array}{c}\text { Corporate culture } \\
\text { among partners in a JV }\end{array}$ & III and VI & $\begin{array}{l}\text { Benchmark practices used by JV partners and standardize } \\
\text { preferred processes. Educate and develop people on how } \\
\text { to use these processes. }\end{array}$ \\
\hline $\begin{array}{l}\text { CM/GC delivery } \\
\text { method piloting }\end{array}$ & III, VI & $\begin{array}{c}\text { Pilot initiatives commonly found in more collaborative } \\
\text { delivery methods such as DB and Integrated Project } \\
\text { Delivery (IPD), e.g., target value design, colocation, open } \\
\text { book, shared risks/rewards. }\end{array}$ \\
\hline
\end{tabular}


The LC practices used in transportation projects found in this study include collaboration initiatives, transparency, root-cause Analysis, visual management (VM), 5S and just-intime delivery. Although some construction companies reported using some LPS elements (i.e., pull planning, planning in different levels), and other Lean practices such as colocation, big rooms, and promoting team engagement, actual proof of the use of LPS was absent. According to findings, it was evident that the DoT management practices used have common ground with those of LC. Throughout the projects, the DoT promoted continuous collaboration with the contractors to deliver projects on time, stay within budget and achieve the desired quality. The DoT was reported to continuously track and evaluate their projects to help them better execute their ongoing and future projects. Furthermore, the DoT was found to utilize LSS to identify problems in their processes and standardize them throughout their offices.

Current construction companies' management practices use CPM as their core master schedule development tool. An upgrade to their management practices by utilizing LPS could help achieve a more stable and smooth workflow, and manage construction crews and tasks. Furthermore, the owner, subcontractors and in-house crews should be invited to collaborate and share their expertise while preparing the project schedule early in the project stages, as reported in interviews III and VI.

The use of the $\mathrm{CM} / \mathrm{GC}$ delivery method is reported to generate various benefits compared to the traditional DBB. Interestingly, DBB is still the method of choice in transportation projects in the State of California, and the State started experimenting with the $\mathrm{CM} / \mathrm{GC}$ delivery method recently. $\mathrm{CM} / \mathrm{GC}$ delivery methods tend to promote early collaboration between key project stakeholders. Contractors' early involvement in the project have resulted in positive impacts, such as: reduced project cost, faster delivery and early risk identification and mitigation, as reported by interviewees. Furthermore, $\mathrm{CM} / \mathrm{GC}$ allowed the creation of joint ventures (JVs) which established a more engaged and collaborative environment between the JV partners and the owner, consequently ensuring better designs and execution of the projects (interviews III and VI).

The second objective of this study was to identify opportunities to use LC practices to deliver these transportation projects. Current construction companies' management practices use CPM as their core schedule development tool. An upgrade to their management practices by utilizing LPS could help achieve a more stable and smooth work flow. Furthermore, subcontractors and in-house crews should be invited to collaborate and share their expertise while preparing the project schedule in early project stages.

Based on the tools utilized by the interviewees in this study, the use of Building Information Modeling (BIM) could improve transparency and promote better visualization of projects. Such a tool could be vital for the owner, designers and contractors as it would enhance their project understanding, provide them with the ability to share input at all stages of the project, and identify constraints facing different trades and designers. Visual management in different forms could be used to improve communication in this sector, as highlighted by Tezel et al. (2016), whether through the use of boards, BIM, or tools to facilitate planning (e.g., LPS) and decision-making (e.g., choosing by advantages). Morever, tools such as root cause analysis (RCA, 5 whys) could be utilized to promote continuous improvement and help identify and eliminate the root cause of problems and avoid their recurrence in future projects. Finally, choosing by advantages (CBA) and benefits realization process could enable better decision-making strategies regarding materials, execution methods, and subcontractors selection. 


\section{CONCLUSIONS}

The study of Lean practices to design and build transportation projects is still in its early days when compared to the use of LC in other sectors of the construction industry. The literature at large, and specifically the IGLC literature, has very few studies on the use of Lean in heavy civil and transportation projects. During this study, the authors found few examples of studies focusing on these sectors. One of the contributions offered by this study was to document the use of Lean in transportation projects, especially in Southern California, and to identify opportunities where the use of Lean would improve the delivery of these projects. The State of California has a large transportation program to be developed over the next several years, and even small improvements in these projects would yield large savings for the State and likely enhance the well-being of the communities affected by having these projects completed on time, on budget, and with the desired quality. Tools and methods used to design, plan, and build the projects covered during the interviews were identified and illustrate how some companies already use Lean-inspired tools, and others could benefit from their use, as outlined in Table 2.

Finally, it is recommended that the transportation sector in the United States learn from other sectors in which the use of Lean is more advanced, e.g., Healthcare, Commercial, Education, as well as from programs in other countries, e.g., Highways England, how Lean can be successfully implemented in the context of transportation projects. Moreover, DoTs have the leverage to support Lean research and education by focusing on supporting studies and education on disseminating Lean practices in Transportation. Given the main obstacles reported by the literature and interviewees (e.g., cost and schedule overruns, utilities, changes), much of DoTs funding in Construction Management research is related to productivity studies, risk analysis, scheduling, and legal issues, to name a few, and very little in actually redefining the operational system that is used in the management of these projects from design to construction. The industry needs to change how these projects are developed and built, and this change involves the use of innovative Lean techniques which promotes a collaborative look at these projects.

\section{ACKNOWLEDGMENTS}

The authors are grateful to those who volunteered their time to participate in the interview process. The analysis and opinions expressed in this paper are those of the authors.

\section{REFERENCES}

Al Heet, M.R.A.H. 2018. Use of Lean Construction Practices in Transportation Construction Projects. MS Thesis, Dept. of Civil, Construction, and Environmental Engineering, San Diego State University.

Fellows, R. and Liu, A.. 2008. Research Methods for Construction. West Sussex, UK: Wiley-Blackwell.

FHWA (Federal Highway Administration). 2017. "Mitigation Strategies for Design Exceptions - Chapter 1: Types of Construction.” Available at: https://bit.ly/2Z9PgW9.

Fullalove, L. H. 2013. "Examples of Lean Techniques and Methodology Applied to UK Road Schemes." Proc. 21st Annual Conference of the International Group for Lean Construction, edited by C. T. Formoso and P. Tzortzopoulos, 1057-66, Fortaleza, Brazil, http://iglc.net/Papers/Details/904. 
Goodrum, P. M., Hancher, D. E. and Yasin, M. 2003. "A Review of Constructability Barriers and Issues in Highway Construction." ASCE, Construction Research Congress, Honolulu, HI.

Hanna, A. S., Wodalski, M. and Whited, G. 2010. "Applying Lean Techniques in Delivery of Transportation Infrastructure Projects." Proc. 18th Annual Conference of the International Group for Lean Construction, 609-19. Haifa, Israel.

Hasan, R., Suliman, S. and Al Malki, Y.. 2014. "An Investigation into the Delays in Road Projects in Bahrain." International Journal of Research in Engineering and Science, 2 (2): 38-47. Available at: https://bit.ly/3bEV8Jt

Highways England. 2016. Lean Support to Highways England. London: Crown. Available at: https://bit.ly/2TePlnr

Koskela, L. 1992.Application of the New Production Philosophy to Construction." CIFE Technical Report \#72, Stanford University, Stanford, CA, September.

Love, P. E. D., Smith, J., Simpson, I., Regan, M. and Olatunji, O. 2015. "Understanding the Landscape of Overruns in Transport Infrastructure Projects." Environment and Planning B: Planning and Design, 42 (3): 490-509.

Park, Y., and Papadopoulou, T.C.. 2012. "Causes of Cost Overruns in Transport Infrastructure Projects in Asia." Built Environment Project and Asset Management, 2 (2): 195-216.

Rebuilding California. 2020. About SB1. http://rebuildingca.ca.gov/ Accessed on 02/04/2020.

Tezel, A., Aziz, Z., Koskela, L., and Tzortzopoulos, P. 2016. "Benefits of Visual Management in the Transportation Sector." In: 24th Annual Conference of the International Group for Lean Construction. Boston, USA, 20-22 Jul 2016.

Transportation Lean Forum - TLF 2020. Transportation Lean Forum. Available at: https://bit.ly/2AyOO9M

Yin, R.K. 2009. "Case Study Research. Design and Methods.” Sage 4 (4): 264-67.

\section{APPENDIX - INTERVIEW GUIDE}

Demographics: 1. What is the type of project you are currently working on?; 2 . What is size of your current project in terms or area covered, dollar value in $\$$, and expected duration?; 3. Who is the owner of this project?; 4. What is the project's main funding source?; 5. What is the delivery method being used? Challenges: 6 . What are the top three challenges you have in this project?; 7. How does your team address these challenges? Management of Design and Construction: 8. Do you use any Lean Construction/Production tools to manage your projects? If you do, which ones and how you use them?; 9. Who is involved with developing the project schedule? What tools are used to develop the schedule?; 10. Who is involved with implementing and distributing the schedule? What tools are used to implement and distribute the schedule?; 11. Are suppliers of material and equipment and service providers (e.g., designers, consultants) required by contract to help with the development of the project schedule? Are they required by contract to attend meetings related to the project schedule? 12. Do you have meetings to discuss the project's design and construction? If so, how often? What tools and documents are used in these meetings? Who participates in these meetings?; 13. How do you keep track and evaluate the performance of different activities in your projects? What do you do with any performance indicator collected from the schedule?; 14. What other tools are used to manage the design and construction of the project? Can you list them and provide examples on how they are used? 